\title{
Numerical approach for extraction of photovoltaic generator single-diode model parameters
}

\author{
Abdelaaziz Benahmida ${ }^{1}$, Noureddine Maouhoub ${ }^{2}$, Hassan Sahsah ${ }^{3}$ \\ ${ }^{1,3}$ Laboratory of Metrology and Information Processingment Departement of Physics, Faculty of Sciences, Ibn Zohr \\ University, Agadir, Morocco \\ ${ }^{2}$ Laboratory of Electronics, Signal Processing and Physical Modeling, Department of Physics, Faculty of Sciences, Ibn \\ Zohr University, Agadir, Morocco
}

\begin{tabular}{l}
\hline \hline Article Info \\
\hline Article history: \\
Received Aug 8, 2020 \\
Revised Feb 17, 2021 \\
Accepted Mar 4, 2021 \\
\hline
\end{tabular}

\section{Keywords:}

I-V characteristics Least square method Module irradiance Module temperature Single diode model

\begin{abstract}
In this work, a numerical approach has been proposed to estimate the five single-diode circuit model physical parameters of photovoltaic generators from their experimental current-voltage characteristics. Linear least square method has been used to solve the system of three linear equations to express the shunt resistance, the saturation current and the photocurrent as a function of the series resistance and the ideality factor. Two key points have been used to solve the system of two nonlinear equations to extract values of series resistance and ideality factor. The advantage of the proposed method with respect of existing numerical techniques is that use only two key points of the experimental characteristic and need only two initial guesses and does not use any approximation. To evaluate the proposed method, three PV generators data have been used to compare the experimental and the theoretical curves. The application of the proposed method provides a good agreement with the experimental.
\end{abstract}

This is an open access article under the $\underline{C C B Y-S A}$ license.

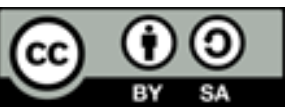

\section{Corresponding Author:}

Noureddine Maouhoub

Laboratory of Electronics, Signal Processing and Physical Modeling

Department of Physics, Faculty of Sciences

Ibn Zohr University

BP 8106, Agadir, Morocco

Email: n.maouhoub@uiz.ac.ma

\section{INTRODUCTION}

The photovoltaic (PV) generator is the basic element of the photovoltaic system. This element is made of semiconductor material with a p-n junction which has the property of, when exposed to sunlight, producing direct current electricity proportional to the solar irradiation. The behavior of PV generator has a non-linear current-voltage (I-V) characteristic. Various representations have been employed to describe the currentvoltage (I-V) relationship in solar cells. In practice, the single diode model is the commonly equivalent circuit used to describe the I-V relationship. However, regardless of this model, there are important PV parameters that must be accurate and extracted for the simulation, design, performance, evaluation and control of PV systems. The five main parameters that describe the behavior of PV generator models are the generated photocurrent $\left(I_{\mathrm{ph}}\right)$, the saturation current $\left(\mathrm{I}_{0}\right)$, the series resistance $\left(\mathrm{R}_{\mathrm{s}}\right)$, shunt resistance or parallel resistance $\left(R_{p}\right)$ and the diode ideality factor (n). The electric current produced by a solar cell depends on the intensity of the incident light and its properties.

Several methods have been suggested in the literature to extract the five parameters. We can divide these methods into three categories: analytical, numerical and evolutionary methods [1]-[22]. N. Maouhoub 
[15] has proposed an analytical method to determine the five physical parameters. The key points have been used to calculate the series resistance and the ideality factor. The linear least square technique has been used to determine to parallel resistance, the photo current and the saturation current. F. Ghani et al. [16] provided a numerical method to extract the values of the series and shunt resistors using the Newton-Raphson algorithm and the Lambert $\mathrm{W}$ - function. A singularity problem, which is divided by zero, can occur if the initial conditions of the parameters are incorrectly chosen. Moreover, these methods require many assumptions to simplify the problem of extracting the five parameters. C. Zhang et al. [17] proposes a simple and efficient numerical method for extracting all the parameters of a solar cell from a single current-voltage (I-V) curve under constant illumination by reducing the parameters to three. The disadvantage of this approach is that it allows several simplifications by eliminating terms of the analytical equation of current (I-V). Hejri et al. [18] proposed a numerical procedure using three key points from manufacturer's data sheets and by solving a system of four nonlinear equations; this method needs four suitable initial guesses. Recently, Stornelli et al. [19] proposed a new simplified method for the iterative estimation of the five PV module parameters. This method uses some approximations to determine the values of $\mathrm{R}_{\mathrm{s}}$ and $\mathrm{n}$. Yadir et al. [20] proposed another numerical method based on key points and solving a system of four nonlinear equations. El Achouby et al [21] proposed numerical method to extract the five physical parameters, operating at standard test conditions (STC). This method is based on the variation of the ideality factor and solving a system of four nonlinear equations. The problem of this iterative method is that needs suitable initial values of four physical parameters.

In the present work, we propose a numerical approach to extract the five physical parameters based on the single diode model. In a first step, we formulate three analytical expressions of the parallel resistance $R_{\mathrm{p}}$, the photocurrent $\mathrm{I}_{\mathrm{ph}}$ and the saturation current $I_{0}$ using the linear least square method. These three expressions depend on the diode ideality factor $n$ and the series resistance $R_{s}$. Then, we extract these two parameters numerically by solving a nonlinear system of two transcendent equations at two key points, namely, a short circuit point and maximum power point. The proposed method has the advantage over other methods of employing only two key points of the experimental I-V curve and only two initial guesses and does not use any approximation and any computing of the slope at open-circuit voltage or at short-circuit current. To check the precision of our method, we extract the five physical parameters of the commercial RTC PV cell, the PWP201 PV module and the KC200GT PV module and we compare the theoretical current-voltage curve with the experimental one. We organize our paper into four sections. After an introduction, we present in the second section the one-diode equivalent circuit model and the proposed five-parameter extraction methods. In the third section, we use three photovoltaic generators experimental data to validate our proposed method and to compare with other methods; we evaluate the accuracy of the presented method by calculating the absolute error and the root mean square error. Finally, we close our paper with a conclusion.

\section{PROPOSED METHOD}

\subsection{Single diode model}

In our study, we use the equivalent single diode circuit model to describe the behavior of the photovoltaic generator. This circuit is illustrated in the Figure 1.

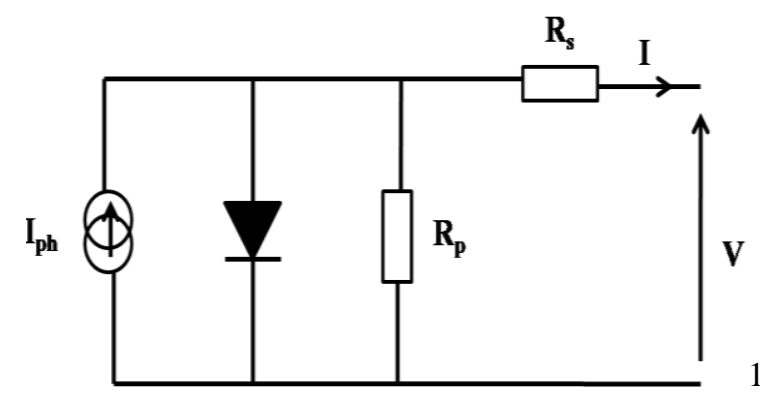

Figure 1. Electrical circuit for single diode PV model

The output current of the PV generator, with five parameters, is a function of the output voltage:

$$
I=I_{p h}-I_{0}\left(\exp \left(\frac{V+R_{s} \cdot I}{n \cdot N_{s} \cdot V_{t h}}\right)-1\right)-\frac{V+R_{s} \cdot I}{R_{p}}
$$


The five parameters of this model are: the shunt resistance $R_{p}$, the saturation current $I_{0}$, the photocurrent $\mathrm{I}_{\mathrm{ph}}$, the ideality factor $\mathrm{n}$ and the series resistance $\mathrm{R}_{\mathrm{s}}$.

- $\quad \mathrm{N}_{\mathrm{s}}$ is the number of cells in series in the PV module ( $\mathrm{Ns}=1$ for one solar cell),

- $\quad \mathrm{V}_{\mathrm{th}}=\mathrm{k}_{\mathrm{B}} \mathrm{T} / \mathrm{q}$ is the thermal voltage,

- $\quad \mathrm{q}$ is the electronic charge,

- $\quad \mathrm{k}_{\mathrm{B}}$ is the Boltzman's constant

- $\quad \mathrm{T}$ is the temperature in Kelvin. Lambert (2).

This (1) is a nonlinear transcendent equation. We can write the current $\mathrm{I}=\mathrm{f}(\mathrm{V})$ by introducing the

$$
I=\frac{I_{0}+I_{p h}}{1+R_{s} \cdot G_{p}}-\frac{G_{p}}{1+R_{s} \cdot G_{p}} V-\frac{n \cdot V_{t h}}{R_{s}} \operatorname{LambertW}\left(\frac{I_{0} \cdot R_{s}}{n \cdot V_{t h} \cdot\left(1+R_{s} \cdot G_{p}\right)} \exp \left(\frac{V+R_{s} \cdot\left(I_{0}+I_{p h}\right)}{n \cdot V_{t h} \cdot\left(1+R_{s} \cdot G_{p}\right)}\right)\right)
$$

\subsection{Proposed five parameters estimation method}

\subsubsection{Analytical expressions of $I_{0}, I_{p h}$ and $R_{p}$}

According to our previous works $[11,15]$, we rewrite the (1) as (3).

$$
I_{i}=I_{p h}-I_{0} \cdot A_{i}-G_{p} \cdot B_{i}
$$

Where

$$
\left\{\begin{array}{l}
A_{i}=\exp \left(\frac{V_{i, m}+R_{s} I_{i, m}}{n N_{s} V_{t h}}\right)-1 \\
B_{i}=V_{i, m}+R_{s} I_{i, m}
\end{array}\right.
$$

$\mathrm{V}_{\mathrm{I}, \mathrm{m}}$ is the measured voltage of the PV generator and $\mathrm{N}$ is the number of measured points. In order to formulate the analytical expression of $\mathrm{I}_{\mathrm{ph}}, \mathrm{I}_{0}$ and $\mathrm{R}_{\mathrm{p}}$, we use the linear least squares method based on minimizing the follow objective (5).

$$
\mathrm{S}=\sum_{\mathrm{i}=1}^{\mathrm{N}}\left(\mathrm{I}_{\mathrm{i}}-\mathrm{I}_{\mathrm{i}, \mathrm{m}}\right)^{2}
$$

$I_{i, m}$ is the measured current of the PV generator and Ii is the theoretical current given in the (1). After application of this method, we formulate the follow linear system of three equations [15]:

$$
\left\{\begin{array}{l}
\mathrm{I}_{\mathrm{ph}} \mathrm{N}-\mathrm{I}_{0} \sum_{\mathrm{i}=1}^{\mathrm{N}} \mathrm{A}_{\mathrm{i}}-\mathrm{Gp} \sum_{\mathrm{i}=1}^{\mathrm{N}} \mathrm{B}_{\mathrm{i}}=\sum_{\mathrm{i}=1}^{\mathrm{N}} \mathrm{I}_{\mathrm{i}, \exp } \\
-\mathrm{I}_{\mathrm{ph}} \sum_{\mathrm{i}=1}^{\mathrm{N}} \mathrm{A}_{\mathrm{i}}+\mathrm{I}_{0} \sum_{\mathrm{i}=1}^{\mathrm{N}} \mathrm{A}_{\mathrm{i}}{ }^{2}+\mathrm{Gp} \sum_{\mathrm{i}=1}^{\mathrm{N}} \mathrm{B}_{\mathrm{i}} \mathrm{A}_{\mathrm{i}}=-\sum_{\mathrm{i}=1}^{\mathrm{N}} \mathrm{I}_{\mathrm{i}, \exp } \mathrm{A}_{\mathrm{i}} \\
-\mathrm{I}_{\mathrm{ph}} \sum_{\mathrm{i}=1}^{\mathrm{N}} \mathrm{B}_{\mathrm{i}}+\mathrm{I}_{0} \sum_{\mathrm{i}=1}^{\mathrm{N}} \mathrm{B}_{\mathrm{i}} \mathrm{A}_{\mathrm{i}}+\mathrm{Gp} \sum_{\mathrm{i}=1}^{\mathrm{N}} \mathrm{B}_{\mathrm{i}}{ }^{2}=-\sum_{\mathrm{i}=1}^{\mathrm{N}} \mathrm{I}_{\mathrm{i}, \exp } \mathrm{B}_{\mathrm{i}}
\end{array}\right.
$$

Where $G_{p}=1 / R_{p}$

The solution of the previous system, provides three analytical expressions of $I_{p h}(n, R s), I_{0}(n, R s)$ and $R_{p}(n, R s)$ as a function of ideality factor $n$ and series resistance $R_{s}$.

\subsubsection{Numerical extraction of $\mathbf{n}$ and $\mathbf{R s}$}

In order to extract the series resistance $\mathrm{R}_{\mathrm{s}}$ and the ideality factor $\mathrm{n}$, we use two transcendent equations.

By setting $(\mathrm{V}, \mathrm{I})=\left(\mathrm{V}_{\mathrm{mpp}}\right.$, Impp) using (1), we establish a first transcendent equation linking maximum power point to two physical model parameters: 


$$
I_{m p p}=I_{p h}\left(n, R_{s}\right)-I_{0}\left(n, R_{s}\right)\left(\exp \left(\frac{V_{m p p}+R_{s} \cdot I_{m p p}}{n \cdot N_{s} \cdot V_{t h}}\right)-1\right)-\frac{V_{m p p}+R_{s} \cdot I_{m p p}}{R_{p}\left(n, R_{s}\right)}
$$

By setting $\mathrm{V}=0$ using (1), we find a second transcendent equation linking short-circuit current Isc to two physical model parameters:

$$
I_{s c}=I_{p h}\left(n, R_{s}\right)-I_{0}\left(n, R_{s}\right)\left(\exp \left(\frac{R_{s} I_{s c}}{n \cdot N_{s} \cdot V_{t h}}\right)-1\right)-\frac{R_{s} I_{s c}}{R_{p}\left(n, R_{s}\right)}
$$

Equations (7) and (8) are two implicit and nonlinear equations with two unknown $\mathrm{n}$ and $\mathrm{R}_{\mathrm{s}}$. To determine these two values, we solve numerically this system of nonlinear equations via Newton-Raphson method by applying the nonlinear solver "fsolve" in MATLAB environment. To solve this system, suitable values of initial guesses are required. The main advantage of the presented method is that use only two initial guesses and needs only two key points of the experimental curve and does not use any approximation or slope computing. The flowchart in Figure 2 shows the steps involved in carrying out the proposed numerical method.

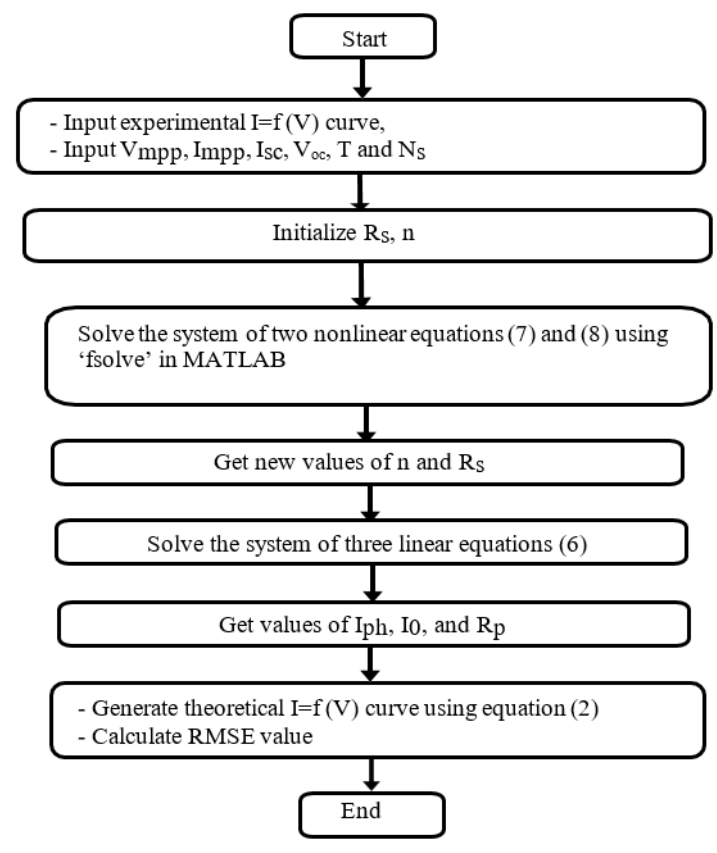

Figure 2. Flowchart of the proposed method

\section{RESULTS AND DISCUSSION}

In order to validate the proposed method, it is examined for three experimental case studies: the Silicon solar cell RTC France at $33^{\circ} \mathrm{C}$ (case study 1), Silicon Module PWP201 at $45^{\circ} \mathrm{C}$ (case study 2), and the KC200GT multi-crystal PV module operating under Standard Test Conditions STC (case study 3). To test the accuracy of our method and to measure the degree of precision of our mathematical model defined above for the extraction of the five parameters, two statistical indicators are selected: the Absolute Error (AE) and the Root Mean Square Error (RMSE) estimator defined as (9) and (10).

$$
\begin{aligned}
& \mathrm{RMSE}=\left[\frac{1}{\mathrm{~N}} \sum_{\mathrm{i}=1}^{\mathrm{N}}\left(\mathrm{I}_{\mathrm{i}}-\mathrm{I}_{\mathrm{i}, \mathrm{m}}\right)^{2}\right]^{\frac{1}{2}} \\
& \mathrm{AE}=\left|\mathrm{I}_{\mathrm{i}}-\mathrm{I}_{\mathrm{i}, \mathrm{m}}\right|
\end{aligned}
$$


The Table 1 shows the physical characteristics extracted from the experimental I-V curve of the three photovoltaic generators RTC France at $33^{\circ} \mathrm{C}$, PWP201 at $45^{\circ} \mathrm{C}$ and $\mathrm{KC} 200 \mathrm{GT}$ at STC. The experimental I-V curves of these two cases are extracted from [1]. For the KC200GT panel, the experimental I-V data are extracted from the datasheet [23] under standard STC test conditions (irradiation level $1000 \mathrm{~W} / \mathrm{m} 2$, AM spectrum 1.5 and cell temperature $25^{\circ} \mathrm{C}$ ).

Table 1. Basic parameters for RTC France cell, PWP201 and KC200GT modules

\begin{tabular}{lcll}
\hline Parameter & $\begin{array}{l}\text { RTC } \\
\left(33^{\circ} \mathrm{C}\right)\end{array}$ & $\begin{array}{l}\text { PWP201 } \\
\left(45^{\circ} \mathrm{C}\right)\end{array}$ & $\begin{array}{l}\text { KC200GT } \\
(\mathrm{STC})\end{array}$ \\
\hline Vmpp (V) & 0.4590 & 12.6490 & 27.11 \\
Impp (A) & 0.6755 & 0.9120 & 7.59 \\
Voc (V) & 0.5727 & 16.7785 & 33.07 \\
Isc (A) & 0.7605 & 1.0317 & 8.21 \\
$\mathrm{Ns}$ & 1 & 36 & 54 \\
$\mathrm{Ki}\left(\mathrm{mA} /{ }^{\circ} \mathrm{C}\right)$ & - & - & 3.18 \\
$\mathrm{Kv}\left(\mathrm{mV} /{ }^{\circ} \mathrm{C}\right)$ & - & - & -123 \\
\hline
\end{tabular}

a. $\quad$ Case Study 1: RTC solar cell

Referring to the numerical method proposed previously, using the data listed in Table 1, we extract the values of the five parameters for the RTC France solar cell. The values, thus obtained in comparison with other proposed numerical approachs [8], [17], [20] are summarized in Table 2. As can be seen, the approach proposed provides a minimum value of (RMSE). The presented method has the advantage of using only two initial guesses, reducing the research space to the two unknown parameters and does not use any approximation and any computing of the slope at open-circuit voltage or at short-circuit current compared to other methods that use four or five initial guesses. Several of these methods determine the values of the slope at open-circuit voltage or at short-circuit current with many approximations.

Table 2. Comparison of the different methods for the RTC France solar cell at $33^{\circ} \mathrm{C}$

\begin{tabular}{lllllll}
\hline & $\mathrm{n}$ & $\mathrm{I} 0[\mu \mathrm{A}]$ & $\mathrm{Iph}(\mathrm{A})$ & $\mathrm{Rs}(\Omega)$ & $\mathrm{Rp}(\Omega)$ & $\mathrm{RMSE}$ \\
\hline Proposed & 1.4877 & 0.3477 & 0.7611 & 0.0349 & 42.9764 & $1.4938 \mathrm{E}-3$ \\
Yadir & 1.4905 & 0.3514 & 0.7611 & 0.0355 & 45.0472 & $1.5555 \mathrm{E}-3$ \\
Zhang & 1.48 & 0.3267 & 0.7607 & 0.036 & 60.24 & $2.0135 \mathrm{E}-3$ \\
Cannizzaro & 1.4899 & 0.3604 & 0.7611 & 0.0355 & 44.8997 & $6.3813 \mathrm{E}-3$ \\
\hline
\end{tabular}

Figure 3 shows the experimental characteristic I-V and the theoretical curve using the five estimated parameters, for RTC France solar cell. Theoretical curves are determined using the (2) and using the five extracted parameters. As it can be ascertained, the theoretical curves are in very agreement with the experimental measurement. Figure 4 shows the plot of the absolute error for RTC France solar cell compared with different methods. It is distinctly indicated that the proposed method in this work has a small error. The absolute error does not exceed $0.003 \mathrm{~A}$.

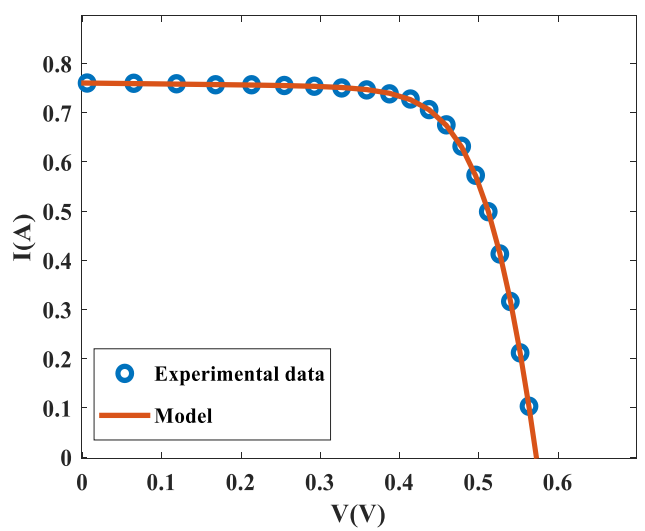

Figure 3. Experimental and theoretical I-V Characteristic for RTC solar cell at $33^{\circ} \mathrm{C}$ 


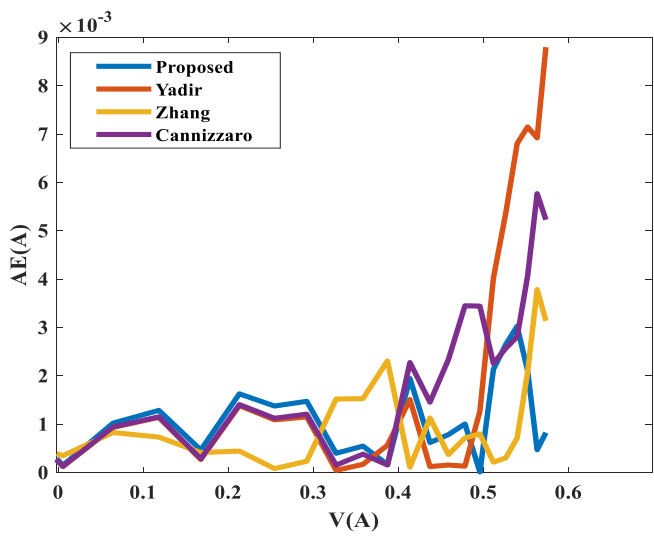

Figure 4. Plot of absolute error vs. voltage for RTC solar cell at $33^{\circ} \mathrm{C}$

b. $\quad$ Case Study 2: PWP PV module

The method previously studied and validated in study case 1, it is applied to the PWP201 module. The extracted values are compared to the work of [2], [7], [17], and are abredged in Table 3. As can be seen, the proposed numerical method provides a very low RMSE value compared to other methods.

Table 3. Comparison of the different methods for the PWP201 module at $45^{\circ} \mathrm{C}$

\begin{tabular}{lllllll}
\hline & $\mathrm{n}$ & $\mathrm{I}_{0}[\mu \mathrm{A}]$ & $\mathrm{I}_{\mathrm{ph}}(\mathrm{A})$ & $\mathrm{R}_{\mathrm{s}}(\Omega)$ & $\mathrm{R}_{\mathrm{p}}(\Omega)$ & $\mathrm{RMSE}$ \\
\hline Proposed & 1.324858 & 2.725395 & 1.033699 & 1.209192 & 625.327 & $2.4096 \mathrm{E}-3$ \\
Bai J & 1.18355 & 0.578317 & 1.03273 & 1.33419 & 1121.67 & $16.495 \mathrm{E}-3$ \\
Chan & 1.3936556 & 5.04906 & 1.03254 & 1.12766 & 1123 & $9.2398 \mathrm{E}-3$ \\
Zhang & 1.27394 & 1.597 & 1.0332 & 1.313 & 602.3 & $6.5819 \mathrm{E}-3$ \\
\hline
\end{tabular}

Figure 5 shows the experimental characteristic I-V and the theoretical curve using the five estimated parameters, for PWP201 module. As we can find out, the theoretical curve is in very good concordance with the experimental measurement extracted from the technical data sheet. Figure 6 shows the absolute error plot for the PWP201 module compared to different methods. It is very clearly indicated that the proposed method in this work has a very low error value compared to other methods. The absolute error does not exceed $0.005 \mathrm{~A}$.

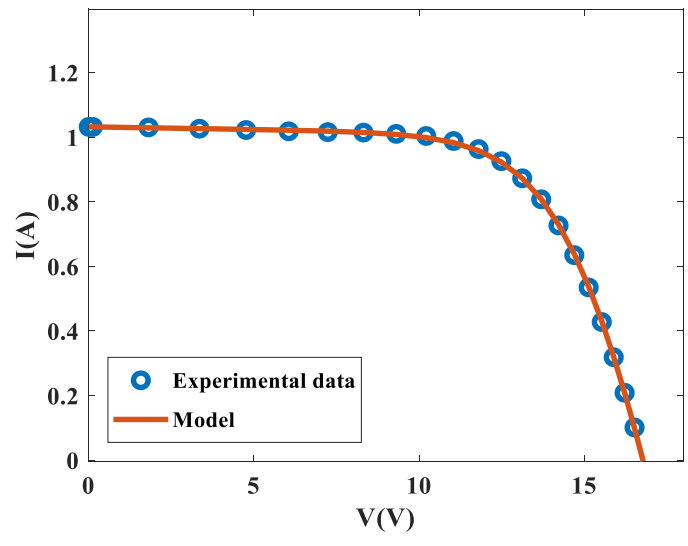

Figure 5. Experimental and theoretical I-V characteristic for PWP201 module at $45^{\circ} \mathrm{C}$

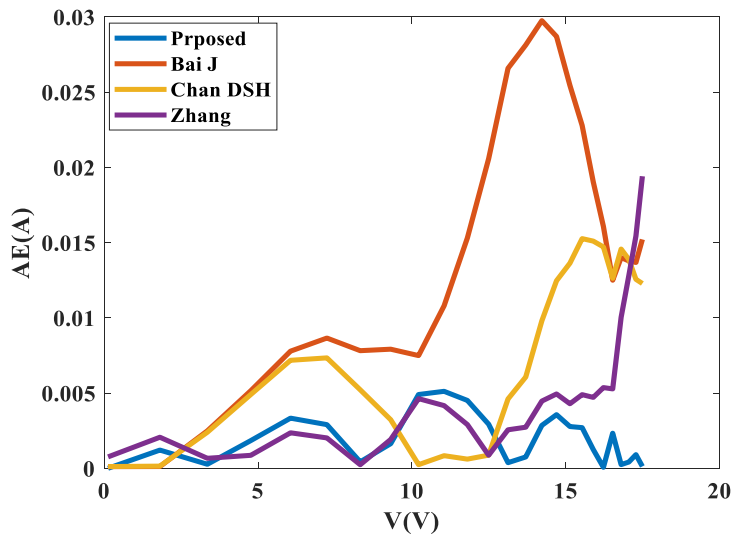

Figure 6. Plot of absolute error vs. voltage for PWP201 solar module at $45^{\circ} \mathrm{C}$

c. Case study 3: KC200GT PV module

The values achieved by this method for KC200GT module are summarized in Table 4. The extracted values are compared with those of other research authors [15], [18], [19]. In Figure 7, we display the absolute 
error curve for the KC200GT module in relation to the several comparison methods. The proposed method has a very low error value and the absolute error does not exceed $0.1 \mathrm{~A}$.

Table 4. Comparison of the different methods for the KC200GT module in STC

\begin{tabular}{lllllll}
\hline & $\mathrm{n}$ & $\mathrm{I}[\mu \mathrm{A}]$ & $\mathrm{Iph}(\mathrm{A})$ & $\mathrm{Rs}(\Omega)$ & $\operatorname{Rp}(\Omega)$ & $\mathrm{RMSE}$ \\
\hline Proposed & 1.089 & 2.56 & 8.225 & 0.229 & 128.96 & 0.04 \\
Maouhoub & 1.0758 & 2.12 & 8.211 & 0.233 & 132.88 & 0.07 \\
Stornelli & 1.1 & 3.27 & 8.196 & 0.2185 & 164.2 & 0.07 \\
Hejri & 1.34 & 171 & 8.21 & 0.220 & 951.93 & 0.15 \\
\hline
\end{tabular}

To study the effect of temperature $\mathrm{T}$ and irradiance level $\mathrm{G}$ on the $\mathrm{I}-\mathrm{V}$ characteristic, we suppose that the influence of the temperature and irradiation on $n, R_{s}$ and $R_{p}$ are negligible [15]. The other two parameters $\mathrm{I}_{\mathrm{ph}}$ and $\mathrm{I}_{0}$ are given by (11) and (12).

$$
\begin{aligned}
& \mathrm{I}_{\mathrm{ph}}(\mathrm{T}, \mathrm{G})=\frac{\mathrm{G}}{\mathrm{G}_{\mathrm{STC}}} \cdot\left(\mathrm{I}_{\mathrm{ph}, \mathrm{STC}}+\mathrm{K}_{\mathrm{i}} \cdot\left(\mathrm{T}-\mathrm{T}_{\mathrm{STC}}\right)\right) \\
& \mathrm{I}_{0}(\mathrm{~T}, \mathrm{G})=\frac{\mathrm{I}_{\mathrm{ph}}(\mathrm{T}, \mathrm{G})-\mathrm{G}_{\mathrm{p}} \cdot \mathrm{V}_{\mathrm{oc}}(\mathrm{T}, \mathrm{G})}{\exp \left(\mathrm{V}_{\mathrm{oc}}(\mathrm{T}, \mathrm{G}) /\left(\mathrm{N}_{\mathrm{s}} \cdot \mathrm{n} \cdot \mathrm{V}_{\mathrm{th}}(\mathrm{T})\right)\right)-1}
\end{aligned}
$$

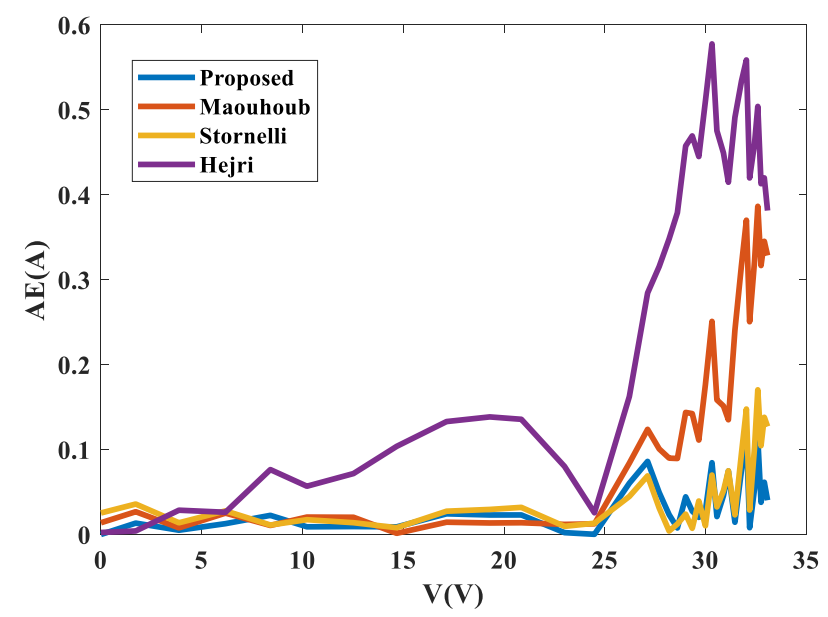

Figure 7. Plot of absolute error vs. voltage for KC200GT at STC

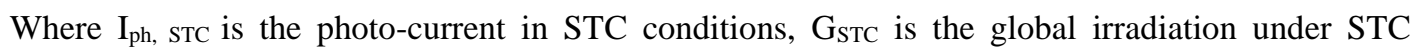
conditions $\left(\mathrm{G}_{\mathrm{STC}}=1000 \mathrm{~W} / \mathrm{m}^{2}\right), \mathrm{T}_{\mathrm{STC}}$ is the temperature under STC conditions $\left(\mathrm{T}_{\mathrm{STC}}=25{ }^{\circ} \mathrm{C}\right)$ and $\mathrm{K}_{\mathrm{i}}$ is the temperature coefficient of $\mathrm{I}_{\mathrm{ph}}$. The temperature and irradiation dependence of $\mathrm{V}_{\mathrm{oc}}$ is given by (13).

$$
\mathrm{V}_{\mathrm{oc}}(\mathrm{T}, \mathrm{G})=\mathrm{V}_{\mathrm{oc}, \mathrm{STC}}+\mathrm{K}_{\mathrm{V}} \cdot\left(\mathrm{T}-\mathrm{T}_{\mathrm{STC}}\right)+\mathrm{n} \cdot \mathrm{N}_{\mathrm{s}} \cdot \mathrm{V}_{\mathrm{th}} \ln \left(\frac{\mathrm{G}}{\mathrm{G}_{\mathrm{STC}}}\right)
$$

$\mathrm{K}_{\mathrm{i}}$ is the temperature coefficient of $\mathrm{V}_{\mathrm{oc}}$ and $\mathrm{V}_{\mathrm{oc}}$, STC is open-circuit voltage in STC conditions. Figure 8 presents the experimental I-V characteristic and the theoretical curve using the five estimated parameters, for the KC200GT PV modules. As can be viewed, the theoretical curve of the above-mentioned $\mathrm{PV}$ module is in very good agreement with the experimental measurement extracted from the data sheet under the conditions of constant temperature $\mathrm{T}=25^{\circ} \mathrm{C}$ and at different irradiation levels. In Figure 9, we plot the experimental I-V characteristic and the theoretical curve, for the KC200GT PV module for fixed irradiation $1000 \mathrm{~W} / \mathrm{m}^{2}$ and at different temperatures. It is clear that the theoretical values of the model are in accord with the experimental measurements. 


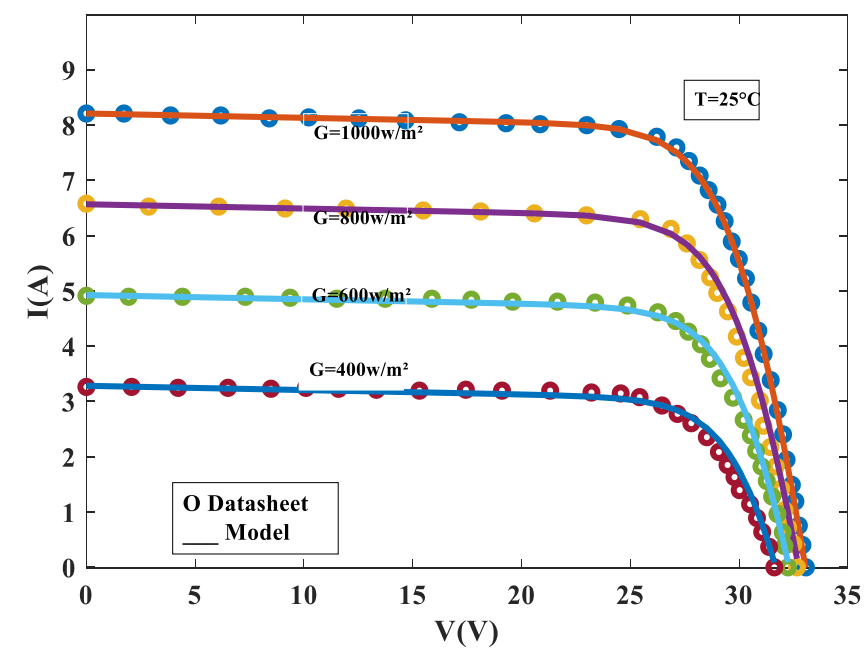

Figure 8. Experimental and theoretical I-V characteristic for KC200GT module under varying irradiance

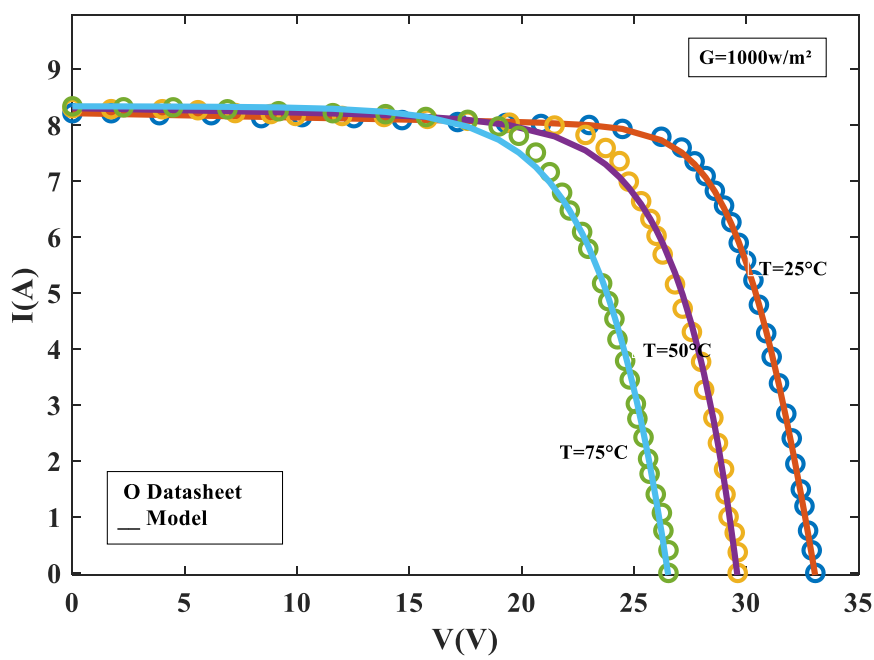

Figure 9. Experimental and theoretical I-V characteristic for KC200GT module under varying temperature

\section{CONCLUSION}

This paper proposed a numerical method to extract and evaluate the physical parameters of photovoltaic generators. The equivalent single-diode circuit with five parameters is applied for modeling the electrical behavior of the PV generators. This technique is based on the analytical extraction of the saturation current, the parallel resistance and the photocurrent as a function of the ideality factor and series resistance using the linear least squares method. Then, the estimation of the series resistance and the ideality factor has been found by solving numerically a system of two nonlinear equations. The suggested numerical method reduces the number of the initial values to two and extract the five parameters without approximation. The application of this method for the RTC France solar cell, PWP201 and the KC200GT panels indicated a low error and a good agreement with the experimental data.

\section{REFERENCES}

[1] Easwarakhanthan, T., Bottin, J., Bouhouch, I., Boutrit, C., "Nonlinear minimization algorithm for determining the solar cell parameters with microcomputers," Int. J. Sol.Energy, vol. 4, no. 1, pp. 1-12, 1986.

[2] D. S. H. Chan and J. C. H. Phang, "Analytical methods for the extraction of solar-cell single- and double-diode model parameters from I-V characteristics," in IEEE Transactions on Electron Devices, vol. 34, no. 2, pp. 286-293, Feb. 1987, doi: 10.1109/T-ED.1987.22920.

[3] K. M. El-Naggar, M. R. AlRashidi, M. F. AlHajri and A. K. Al-Othman, "Simulated Annealing algorithm for photovoltaic parameters identification," Solar Energy, vol. 86, no.1, pp. 266-274, 2012. 
[4] M. K. Munji, W. Okullo, E. E. Van Dyk and F. J. Vorster, "Local device parameter extraction of a concentrator photovoltaic cell under solar spot illumination," Solar Energy Materials and Solar Cells, vol. 94, no. 12, pp. 21292136, 2010.

[5] M. Ye, X. Wang and Y. Xu, "Parameter extraction of solar cells using particle swarm optimization", Journal of Applied Physics, vol. 105, no. 9, pp. 094502, 2009.

[6] H. Al-Hamadi, "Estimation of Photovoltaic Cell Parameters Using Piecewise Linear Approximation," International Journal of Computer Science and Electronics Engineering, vol. 2, no. 1, pp. 2320-4028, 2014.

[7] Bai J, Liu S, Hao Y, et al., "Development of a new compound method to extract the five parameters of PV modules," Energy Convers Manage, vol. 79, pp. 294-303, 2014.

[8] S. Cannizzaro, M. C. Di Piazza, M. Luna and G. Vitale, "PVID: An interactive Matlab application for parameter identification of complete and simplified single-diode PV models," 2014 IEEE 15th Workshop on Control and Modeling for Power Electronics (COMPEL), Santander, pp. 1-7, 2014, doi: 10.1109/COMPEL.2014.6877152.

[9] S. Yadir, S. Aazou, N. Maouhoub, K. Rais, M. Benhmida and E. Assaid, "Illuminated solar cell physical parameters extraction using mathematica," 2009 IEEE/ACS International Conference on Computer Systems and Applications, Rabat, pp. 63-64, 2009, doi: 10.1109/AICCSA.2009.5069303.

[10] N. Maouhoub, "Analytical Identification Method for the Single Diode Model Parameters of a Photovoltaic Panel using Datasheet Values ", Journal of Nano- and Electronic Physics, vol. 9, no 6, p. 06011, 2017.

[11] A. Benahmida, N. Maouhoub, H. Sahsah, H. Mokhliss and K. Rais, "Parameter Identification of Photovoltaic Generators Using an Analytical Approach and Iterative Method," 2019 International Conference of Computer Science and Renewable Energies (ICCSRE), Agadir, Morocco, pp. 1-5, 2019, doi: 10.1109/ICCSRE.2019.8807753.

[12] Awadallah MA. "Variations of the bacterial foraging algorithm for the extraction of PV module parameters from nameplate data ". Energy Convers Manage, vol. 113, no. 1, pp. 312-20, 2016.

[13] Jieming Maa,, Ziqiang Bi , Tiew On Ting, Shiyuan Hao, Wanjun Hao, "Comparative performance on photovoltaic model parameter identification via bio-inspired algorithms ", Solar Energy, vol. 132, no. 1, pp. 606-616, 2016.

[14] Shuijia Li, Wenyin Gong, Xuesong Yan, Chengyu Hu, Danyu Bai, Ling Wang, Liang Gao, "Parameter extraction of photovoltaic models using an improved teachinglearning-based optimization", Energy Conversion and Management, vol. 186, no. 1, pp. 293-305, 2019.

[15] N. Maouhoub, "Photovoltaic module parameter estimation using an analytical approach and least squares method", Journal of Computational Electronics, vol. 17, vol. pp. 784-790, 2018.

[16] F. Ghani, G. Rosengarten, M. Duke and J.K. Carson, "The numerical calculation of single-diode solar-cell modelling parameters", Renew Energy, vol. 1, no .72, pp. 105-12, 2014.

[17] C. Zhang, J. Zhang, Y. Hao, Z. Lin and C. Zhu, "A simple and efficient solar cell parameter extraction method from a single current-voltage curve", Journal of applied physics, vol. 110, no. 6, pp, 10.1063/1.3632971, 2011.

[18] M. Hejri, H. Mokhtari, M. R. Azizian and L. Söder, "An analytical-numerical approach for parameter determination of a five-parameter single-diode model of photovoltaic cells and modules", International Journal of Sustainable Energy, vol. 35, no. 4, pp. 396-410, 2013.

[19] V. Stornelli, M.Muttillo, T.Rubeis and I.Nardi, "A New Simplified Five-Parameter Estimation Method for SingleDiode Model of Photovoltaic Panels", Energies, vol. 12, pp. 4271, 2019.

[20] S. Yadir, R. Bendaoud, A. EL-Abidi, H. Amiry, M. Benhmida, S. Bounouar, B. Zohal, H. Bousseta, A. Zrhaiba, A. Elhassnaoui, "Evolution of the physical parameters of photovoltaic generators as a function of temperature and irradiance: New method of prediction based on the manufacturer's datasheet", Energy Conversion and Management, vol. 203, no. 1, pp. 112141, 2019.

[21] El Achouby, H., Zaimi, M., Ibral, A., Assaid, E.M., "New analytical approach for modelling effects of temperature and irradiance on physical parameters of photovoltaic solar module", Energy Convers. Manag. vol. 177, no. 1, pp. 258-271, 2018.

[22] M. Zaimi, H. El Achouby, A. Ibral, E.M. Assaid, "Determining combined effects of solar radiation and panel junction temperature on all model-parameters to forecast peak power and photovoltaic yield of solar panel under non-standard conditions ". Solar Energy, vol. 191, no. 1, pp 341- 359, 2019.

[23] KC200GT High Efficiency Multicrystal Photovoltaic Module Datasheet Kyocera. 2000. [Online] Available http://www.kyocera.com.sg/products/solar/pdf/kc200gt.pdf. 